\title{
Obesity Associated with Birth Place among Migrant Children in China
}

\author{
Yuancai Zhang1, Yanmin Lin², Yuqiang Li³ ${ }^{3}$ Jinkui $\mathrm{Lu}^{4}$ \\ ${ }^{1}$ School of Sports, Fujian Polytechnic Normal University, Fuqing, China \\ ${ }^{2}$ Physical Education Department, Lvliang University, Lvliang, China \\ ${ }^{3}$ School of Physical Education \& Health Care, East China Normal University, Shanghai, China \\ ${ }^{4}$ School of Sport, Shangrao Normal University, Shangrao, China \\ Email: 1584098650@qq.com, Lym1987@126.com, liyuqiang-123@126.com, *lujinkui628@126.com
}

How to cite this paper: Zhang, Y. C., Lin, Y. M., Li, Y. Q., \& Lu, J. K. (2020). Obesity Associated with Birth Place among Migrant Children in China. Advances in Physical Education, 10, 342-346.

https://doi.org/10.4236/ape.2020.104027

Received: June 29, 2020

Accepted: October 16, 2020

Published: October 19, 2020

Copyright ( $\odot 2020$ by author(s) and Scientific Research Publishing Inc. This work is licensed under the Creative Commons Attribution International License (CC BY 4.0).

http://creativecommons.org/licenses/by/4.0/

\section{(c) (i) Open Access}

\begin{abstract}
Background: Childhood obesity has become one of the most important epidemic problems in the world, both in developed and underdeveloped areas. Purpose: In this study, we aimed to examine the relationship between obesity and the birth place of migrant children in Shanghai, China. Methods: A cross-sectional survey was conducted in April 2018, and a multi-stage, random cluster sampling method was applied. The final sample included 3707 children between 7 to 12 years old (1917 boys and 1790 girls). We conducted anthropometric measurements (height, weight) and questionnaire investigation. Results: Children who were born in north China were more likely to be obese $(\mathrm{OR}=1.23,95 \% \mathrm{CI}=1.01-1.87)$, compared with those who were born in HMT (Hong Kong; Macao and Taiwan). The same goes for East China $(\mathrm{OR}=1.41,95 \% \mathrm{CI}=1.11-2.23)$, Northwest China $(\mathrm{OR}=1.43,95 \% \mathrm{CI}=$ $1.21-3.14)$ and Southwest China $(\mathrm{OR}=1.55,95 \% \mathrm{CI}=1.34-3.29)$ when comparing children who were born in these divisions with those who were born in HMT (Hong Kong; Macao and Taiwan; children born in Northeast China were most likely to be overweight $(\mathrm{OR}=1.94,95 \% \mathrm{CI}=1.63-2.82)$. Conclusion: At the provincial level, we found that Heilongjiang, Chongqing, Liaoning have the highest prevalence of obesity. At the regional level, children born in Northeastern China are the most likely to be obese than those born in HMT (Hong Kong, Macao and Taiwan), among children born in North China, East China, Northwest China and Southwest China.
\end{abstract}

\section{Keywords}

Obesity, Birth Place, Migrant Children, China 


\section{Introduction}

With the continuous progress of the society and the rapid development of the economy, the economic gap between developed and underdeveloped areas is enlarging. After the Reform and Opening, a great many people went to the developed areas to seek job opportunities. As an important component of the floating population, migrant children have also increased rapidly in number. By 2015, there were more than 35 million migrant children under the age of $17(\mathrm{Lu}$, Gong, Yin et al., 2016). Besides, social progress and economic development are directly contributing to the constant improvement of people's living standards and quality of life. People pay more attention to eating and eat more abundantly. The high-fat and high-energy diet habits, which lead to more energy intake, and the increasing number of sit-ins, directly lead to the increase of overweight and obesity year by year (WHO, 2010; Li, \& Ma, 2002). Nowadays, obesity has become one of the most important epidemic problems in the world; especially childhood obesity is a key public health issue in both developed and underdeveloped areas (Reilly, 2006).

Some studies show that migrant children have dysplasia and a lot of common diseases (Hu, Cook, \& Ma, 2008; Yan, 2005), and it was reported that they are experiencing overweight and obesity in these individuals, which is associated with socioeconomic status and eating habits (Lu, Yin, Deng, \& Liu, 2017; Lu, Yin, Xiong, Liu et al., 2015), while socioeconomic status and lifestyle vary from region to region. This study aimed to examine the relationship between obesity and the birth place of migrant children in Shanghai, China, and to provide theoretical basis for the prevention of obesity in migrant children.

\section{Materials and Methods}

\subsection{Study Participants}

A cross-sectional survey was conducted in April 2018, and a multi-stage, random cluster sampling method was applied. The final sample included 3707 children between 7 to 12 years old (1917 boys and 1790 girls). We conducted anthropometric measurements (height, weight) and questionnaire investigation. Informed consent was obtained from the parents of all subjects. The study was approved by the Ethics Committee of School of Physical Education and Health of East China Normal University.

\subsection{Definition of Overweight and Obesity}

Overweight and obesity were classified according to age- and gender-specific BMI cutoff points which developed for Chinese children (Group of China Obesity Task Force, 2004).

\subsection{Methods}

We calculated BMI according to the formula: weight $(\mathrm{kg}) /$ height $\left(\mathrm{m}^{2}\right)$, and used the BMI standards of Chinese children and adolescents to define wasting weight, 
normal weight, overweight and obese weight (Group of China Obesity Task Force, 2004). Firstly, we compared the percentage of obesity in migrant children according to the birth place (province); secondly, China was divided into eight parts: 1) North China (Beijing; Tianjin; Hebei; Shanxi; Inner Mongol); 2) Northeast China (Heilongjiang; Liaoning; Jilin); 3) East China (Shandong; Jiangsu; Anhui; Jiangxi; Zhejiang; Fujian; Shanghai); 4) Central China (Hubei; Hunan; Henan); 5) South China (Guangdong; Guangxi; Hainan); 6) Northwest China (Ningxia; Xinjiang; Qinghai; Gansu; Shanxi); 7) Southwest China (Sichuan; Guizhou; Yunnan; Tibet; Chongqing); 8) HMT (Hong Kong; Macao and Taiwan). Thirdly, a logistic regression was used to analyze the association between birth place (province) and obesity. All statistical analyses were performed using SPSS 22.0 (IBM, Armonk, NY, USA).

\section{Results}

Figure 1 shows the obese percentage in different birth places, we can find that the prevalence of obesity in Heilongjiang was the highest among all the provinces $(37.5 \%)$, followed by Chongqing (27.8\%), Liaoning (26\%) and then Hunan (1.1\%). No obesity was detected in Guangxi, Tianjin, Xinjiang, Yunnan, Tibet, Jilin and Macao.

We conducted the logistic regression for both obesity and birth place (regional division of China) while controlling for children's gender and age. Children who were born in north China were more likely to be obese $(\mathrm{OR}=1.23,95 \% \mathrm{CI}=$ 1.01 - 1.87), compared with those who were born in HMT (Hong Kong; Macao and Taiwan). The same goes for East China $(\mathrm{OR}=1.41,95 \% \mathrm{CI}=1.11-2.23)$, Northwest China $(\mathrm{OR}=1.43,95 \% \mathrm{CI}=1.21-3.14)$ and Southwest China $(\mathrm{OR}=$ $1.55,95 \% \mathrm{CI}=1.34-3.29)$ when comparing children who were born in these divisions with those who were born in HMT (Hong Kong; Macao and Taiwan), children born in Northeast China were most likely to be overweight $(\mathrm{OR}=1.94$, $95 \% \mathrm{CI}=1.63-2.82)($ Table 1$)$.

Table 1. Birth place (regional division of China) associated with obesity in rural-to-urban migrant children by logistic regression.

\begin{tabular}{cccc}
\hline Variable & \multicolumn{3}{c}{ Obesity } \\
\cline { 2 - 4 } & OR & $95 \%$ CI & $P$-value \\
\hline Regional division of China & & & \\
\hline South China & 0.71 & $0.20-2.56$ & 0.689 \\
Central China & 1.04 & $0.65-2.26$ & 0.231 \\
North China & 1.23 & $1.01-1.87$ & 0.044 \\
East China & 1.41 & $1.11-2.23$ & 0.034 \\
Northwest China & 1.43 & $1.21-3.14$ & 0.049 \\
Southwest China & 1.55 & $1.34-3.29$ & 0.008 \\
Northeast China & 1.94 & $1.63-2.82$ & 0.012 \\
HMT (Hong Kong; Macao and Taiwan) & 1 & - & - \\
\hline
\end{tabular}




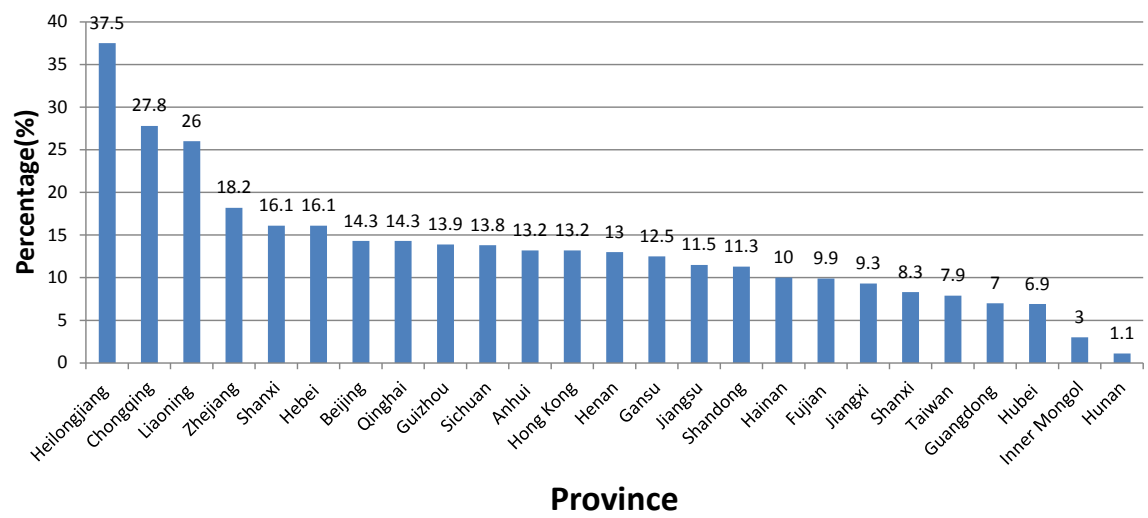

Figure 1. Birth place (province) associated with the prevalence of obesity in migrant children.

\section{Conclusion}

In conclusion, Heilongjiang, Chongqing, Liaoning have the highest prevalence of obesity at the provincial level. In terms of regional division, children who were born in Northeast China are most likely to be obese than those in HMT (Hong Kong, Macao and Taiwan), among children who were born in North China, East China, Northwest China and Southwest China. Therefore, ensuring enough attention to obesity in these areas is of great significance in controlling overweight and obesity in rural-to-urban migrant children.

\section{Acknowledgements}

We wish to thank the cohort study investigators, specifically SC Li, SJ Yin, GD Wang, JH Zhu. This study was supported by Jiangxi Province Social Science University Humanity (18TY10).

\section{Conflicts of Interest}

The authors declare no conflicts of interest regarding the publication of this paper.

\section{References}

Group of China Obesity Task Force (2004). Body Mass Index Reference Norm for Screening Overweight and Obesity in Chinese Children and Adolescents. Chinese Journal of Epidemiology, 25, 97-102.

Hu, X., Cook, S., \& Salazar, M. A. (2008). Internal Migration and Health in China. The Lancet, 372, 1717-1719. https://doi.org/10.1016/S0140-6736(08)61360-4

Li, Y. P., \& Ma, G. S. (2002). Effects of TV Time on Obesity in Children. Foreign Medicine (Hygienics Section), 29, 115-118. https://doi.org/10.1080/1476085022000036862

Lu, J. K., Gong, J. H., Yin, X. J. et al. (2016). Association of Socioeconomic and Lifestyle Behavioral Factors with Obesity and Thinness among Migrant Peasant Workers' Children, by Comparison with Rural and Urban Children in China. International Journal of Clinical and Experimental Medicine, 9, 19611-19622.

Lu, J. K., Yin, X. J., Deng, Y. Q., \& Ji, L. (2017). High Socioeconomic Status and Key Risk 
Factors of Overweight and Obesity among Rural-to-Urban Migrant 7-10y-Old Children in Shanghai, China. Iranian Journal of Public Health, 46, 420-421.

Lu, J. K., Yin, X. J., Xiong, J. P., Liu, J. J., Watanabe, T., \& Tanaka, T. (2015).Comparison of the Status of Overweight/Obesity among the Youth of Local Shanghai, Young Rural-to-Urban Migrants and Immigrant Origin Areas. International Journal of Clinical and Experimental Medicine, 8, 2804-2814.

Reilly, J. J. (2006). Obesity in Childhood and Adolescence: Evidence Based Clinical and Public Health Perspectives. Postgraduate Medical Journal, 82, 429-437.

https://doi.org/10.1136/pgmj.2005.043836

WHO (2010). Global Recommendations on Physical Activity for Health (pp. 16-45). Geneva: WHO.

Yan, Z. (2005). Comparison of Health and Behavior in Migrant Peasant Worker's Children. Hangzhou: Zhejiang University. 